\title{
TRÁFICO MARÍTIMO \\ Y COMERCIAL A TRAVÉS DE \\ UN REGISTRO DE FLETES (1827)
}

M. del Carmen Larrucea

Tradicionalmente, la actividad mercantil ha tenido en Cataluña un papel preponderante. Concretamente por lo que se refiere a nuestra ciudad, el tráfico marítimo portuario ha sido un elemento configurador en la dimensión comercial de nuestra economia.

Desde la antigüedad, el mar ha sido el centro e instrumento de transacciones y conducciones que en su interrelación constante crearon relaciones de comercio.

Los elementos determinantes de la circulación de mercancias a través del mar han sido los diversos instrumentos mercantiles donde se han documentado las aludidas relaciones de comercio. Eminente protagonista en su función instrumental y mediadora ha sido el flete, que es un contrato marítimo en su sentido estricto en el precio o contrapartida pagada por el transporte de mercancías por mar. Tanto en el flete como en el «mercado de fletes" aparecen diversos sujetos: cargadores, corredores marítimos, bolsas de comercio marítimo, armadores, navieras e incluso capitanes que poseían importantes participaciones en el otorgamiento de estos contratos de fletamiento.

Los sujetos, las mercancías y la naturaleza del transporte convierten el mercado de fletes en un mercado que goza de ciertas peculiaridades y que posee una íntima conexión con las rutas y tráficos marítimos. 
Como en todo mercado, opera la ley de la oferta y la demanda, que hace que los fletes sean libres y estén vinculados a las oscilaciones propias de los ciclos económicos que harán que en determinadas situaciones, cuando el mercado esté sometido a fuertes fluctuaciones, la autoridad administrativa fijará los fletes transformándolos en «fletes fijos».

Este mercado está caracterizado por la acusada sensibilidad que posee a cualquier evento de orden económico, social, politico o de cualquier otra naturaleza que sean, hasta el punto de ser aquel una especie de pulso sensible del comercio mundial y de las consecuencias que tiene sobre éste cualquier clase de acontecimientos.

En ocasiones no ya el hecho ocurrido, sino su mera expectativa en estado de inminencia es lo que determina una alza o una baja, o, por el contrario configura una tónica de mercado. La constancia de las actividades mercantiles de esta bolsa de comercio marítimo, sus crisis, sus alzas, las diferentes mercancías que transportan los barcos, las clases de éstos, trayectos, etc. se traducen en una verdadera documentación, a través de cuyos textos podemos crear e interpretar la historia. La fuente de estos conocimientos será los «registros de fletes».

Será necesario conocer la realidad del comercio marítimo en Cataluña a finales del siglo XVIII. Sabemos que hubo un renacimiento comercial con la fundación de la Junta de Comercio, por Fernando VI en $1758^{1}$. Esta Institución organiza la prosperidad de Cataluña y se inspira en el bello lema de la Lonja de Mar de Barcelona: «Terra dabit merces undaque divitias», "La tierra da frutos y la mar, riquezas». He aquí que la Junta de Comercio circundó la tierra y el mar con la gran palanca de una Cataluña renaciente. La constitución de la Junta de Comercio coincide con la fundación de la Compañía de Barcelona, la primera que se crea en Cataluña para comerciar con América. Esta compañía constituída por acciones se abre con un capital de un millón de pesos, con reserva de ampliación de capital. En

I Carreras y Candi, Francesc, Geografía General de Catalunya, Catalunya, p. 1.073 . 
sus estatutos establece que las mercancias que se transportasen en las naves fueran del Principado de Cataluña o de las demás provincias de España, a no ser que sean productos que no se produzcan en la Península.

Asimismo, los capitanes, pilotos, oficiales o tripulantes que la Compañía tenía derecho a nombrar para sus naves debían ser catalanes o del resto de España.

En 1778 Carlos III publicó las famosas Ordenanzas, y declaraba libre el comercio de América con todos los puertos de España, con la excepción de los de Vizcaya, que tenían completa libertad de comercio con el extranjero y recibian los productos coloniales desde Europa.

Diez años después se abre el mercado de las Indias a toda España, las exportaciones ascienden a 76 millones de pesetas y lo que se recibe en la Península desde América, a 201 millones.

En Cataluña se dio un acusado auge, y al ampliar el campo de su actividad mercantil se produjo un renacimiento de la marina y del comercio. La Junta de Comercio, movida por la atracción del antiguo Oriente, fleta un barco para llevar allí los productos de Ultramar. Cataluña se convierte en país de tránsito entre América y Oriente.

Desde que las naves catalanas abren rumbo al gran mar, las Atarazanas reviven y la navegación adquiere una nueva forma que dará lugar al desarrollo de una fecunda costumbre marítima: la Mota. Dicha costumbre, legislada en el Costum de Tortosa y en el Llibre del consolat del Mar, se basa en la participación de los marineros en el resultado del viaje (navegar a la par).

El capitán, en virtud de este contrato, se convierte en un gerente de una casa comercial flotante, que invierte el capital en las mercancías que considera más ventajosas, que emprende sus viajes, va a los países que le parecen mejor, compra nuevas mercancias y va navegando hasta que finaliza la expedición y rinde cuentas, repartiendo los beneficios o las pérdidas a los accionistas o personas ${ }^{2}$.

Las embarcaciones de vela resultaban factorías comerciales en

${ }^{2}$ Op. cit., p. 1.089 . 
las que el capitán disfrutaba de libertad para emprender sus negocios y viajes. Esta actividad mercantil favoreció la expansión comercial de Cataluña; los pueblos de la costa: el Masnou, Vilasar y Lloret tenían una flota de 200 veleros «de carrera d'Amèrica).

Los contratos marítimos, comercio, náutica, etc. estaban regulados por el Consolat del Mar, que constituía una verdadera jurisdicción en el ámbito marítimo, y que dirimía con sus decisiones todos los conflictos del mar. Todas sus resoluciones y prácticas consuetudinarias han llegado hasta nuestros días gracias al Llibre del Consolat del Mar, pieza clave en la creación del derecho marítimo del Mediterráneo ${ }^{3}$.

Cataluña, que posee el mercado de América y que ha perfeccionado sus medios con las escuelas de la Junta del comercio, que trabajaban conjuntamente en la perfección de la náutica, adquiere una preponderancia en el comercio marítimo. Los puertos habilitados para América eran los Alfaques, Tarragona y Barcelona. No podían embarcar más que los artículos del pais, y las naves tenian que ser construídas en España y por armadores españoles.

El comercio marítimo con América quedó cortado con la guerra de la independencia americana. Nos vimos obligados a buscar otros mercados y a afianzar los antiguos que teníamos en Europa. Prueba de ello es el Registro de Fletes que vamos a exponer: pertenece al año 1827 , su titulación original es «Hoja de entradas del extranjero desde la núm. 2.562 a la 2.799 » y corresponde al mes de diciembre ${ }^{4}$.

${ }^{3} \mathrm{JAL}, \mathrm{A} .$, Glossaire nautique, repertoire polyglotte de termes de marine anciens et modernes, París 1848, p. 506.

4 ACA, Sección de Hacienda, Registro núm. 4264. 


\begin{tabular}{|c|c|c|c|c|}
\hline Tartana & Española & $\begin{array}{l}\text { Marsella } \\
\text { y Sète }\end{array}$ & Sederías & 2.562 \\
\hline Polacra & Española & Génova & $\begin{array}{l}\text { Algodón } \\
\text { hilado }\end{array}$ & 2.563 \\
\hline Falucho & Española & Génova & $\begin{array}{l}\text { Algodón } \\
\text { hilado }\end{array}$ & 2.564 \\
\hline Bergantín & Sueca & Estocolmo & $\begin{array}{l}\text { Tablas y tablo- } \\
\text { nes de pino }\end{array}$ & 2.565 \\
\hline Tartana & Española & $\begin{array}{l}\text { Marsella y } \\
\text { Sète }\end{array}$ & $\begin{array}{l}\text { Queso } \\
\text { y azúcar }\end{array}$ & 2.566 \\
\hline aud & Española & Marsella & Lencería & 2.567 \\
\hline Queche & Española & Bilbao & $\begin{array}{l}\text { Hierro, plan- } \\
\text { chuela }\end{array}$ & 2.568 \\
\hline Falucho & Española & Génova & $\begin{array}{l}\text { Algodón } \\
\text { hilado }\end{array}$ & 2.569 \\
\hline Bergantín & Inglesa & Liverpool & $\begin{array}{l}\text { Algodón } \\
\text { hilado }\end{array}$ & 2.570 \\
\hline Falucho & Española & Génova & $\begin{array}{l}\text { Algodón } \\
\text { hílado }\end{array}$ & 2.571 \\
\hline Laud & Española & Marsella & $\begin{array}{l}\text { Relojes } \\
\text { de plata }\end{array}$ & 2.572 \\
\hline Polacra & Española & Génova & $\begin{array}{l}\text { Algodón } \\
\text { hilado }\end{array}$ & 2.573 \\
\hline Bergantín & Sueca & Cristiansand & $\begin{array}{l}\text { Bacalao } \\
\text { y pez palo } \\
\text { Tablas } \\
\text { y tablones }\end{array}$ & 2.574 \\
\hline Tartana & Española & $\begin{array}{l}\text { Marsella } \\
\text { y Sète }\end{array}$ & $\begin{array}{l}\text { Pañuelos } \\
\text { de lana }\end{array}$ & 2.575 \\
\hline Bergantín & Sueca & $\begin{array}{l}\text { Drontheim } \\
\text { y Gibraltar }\end{array}$ & Bacalao & 2.576 \\
\hline Javeque & Espan̂ola & $\begin{array}{l}\text { Génova y } \\
\text { Portvendres }\end{array}$ & Pimienta negra & 2.577 \\
\hline
\end{tabular}




\section{Clase de Nacionalidad Procedencia Mercaderias Núm. Hoja}

barco

\begin{tabular}{|c|c|c|c|c|}
\hline Goleta & Española & Génova, & Pimienta negra & 2.578 \\
\hline Fartana & Española & $\begin{array}{l}\text { Marsella } \\
\text { y Sète }\end{array}$ & Quesos & 2.579 \\
\hline Tartana & Española & Francia & $\begin{array}{l}\text { Libros: } 50 \mathrm{~g} \\
\text { francesas }\end{array}$ & 2.580 \\
\hline Bombarda & Española & Marsella & $\begin{array}{l}\text { Algodón } \\
\text { en rama }\end{array}$ & 2.581 \\
\hline \multicolumn{5}{|l|}{ Bergantín } \\
\hline Polacra & Sarda & $\begin{array}{l}\text { Gibraltar } \\
\text { y Mahón }\end{array}$ & $\begin{array}{l}\text { Algodón } \\
\text { en rama }\end{array}$ & 2.582 \\
\hline Polacra & Sarda & $\begin{array}{l}\text { Gibraltar } \\
\text { y Mahón }\end{array}$ & $\begin{array}{l}\text { Algodón } \\
\text { en rama }\end{array}$ & 2.583 \\
\hline Bombarda & Sarda & $\begin{array}{l}\text { Gibraltar } \\
\text { y Mahón }\end{array}$ & $\begin{array}{l}\text { Algodón } \\
\text { en rama }\end{array}$ & 2.584 \\
\hline Bergantin & Sueca & Estocolmo & $\begin{array}{l}\text { Vigas } \\
\text { y alquitrán }\end{array}$ & 2.585 \\
\hline Falucho & Española & Marsella & Aguarrás & 2.586 \\
\hline Bergantín & Sarda & Lisboa & $\begin{array}{l}\text { Algodón } \\
\text { en rama }\end{array}$ & 2.587 \\
\hline Galea & Holandesa & Lisboa & $\begin{array}{l}\text { Algodón } \\
\text { en rama }\end{array}$ & 2.588 \\
\hline Galea & Holandesa & Lisboa & $\begin{array}{l}\text { Algodón } \\
\text { en rama }\end{array}$ & 2.589 \\
\hline Goleta & Sueca & Bergen & Bacalao & 2.590 \\
\hline Bergantín & Española & Marsella & $\begin{array}{l}\text { Algodón } \\
\text { en rama }\end{array}$ & 2.591 \\
\hline Bergantín & Sueca & Cristiansand & $\begin{array}{l}\text { Bacalao } \\
\text { y pez palo }\end{array}$ & 2.592 \\
\hline Bergantín & Sueca & Bouvregullusen & $\begin{array}{l}\text { Bacalao } \\
\text { y pez palo }\end{array}$ & 2.593 \\
\hline Falucho & Española & Marsella & $\begin{array}{l}\text { Hilaza cruda } \\
\text { y blanca }\end{array}$ & 2.594 \\
\hline Lugre & Española & San Scbastián & $\begin{array}{l}\text { Hierro } \\
\text { en matas }\end{array}$ & 2.595 \\
\hline Falucho & Española & Marsella & Sederia & 2.596 \\
\hline Bergantin & Inglesa & I.iverpool & $\begin{array}{l}\text { Algodón } \\
\text { en rama }\end{array}$ & 2.597 \\
\hline Galea & Holandesa & Lisboa & $\begin{array}{l}\text { Algodón } \\
\text { en rama }\end{array}$ & 2.598 \\
\hline
\end{tabular}




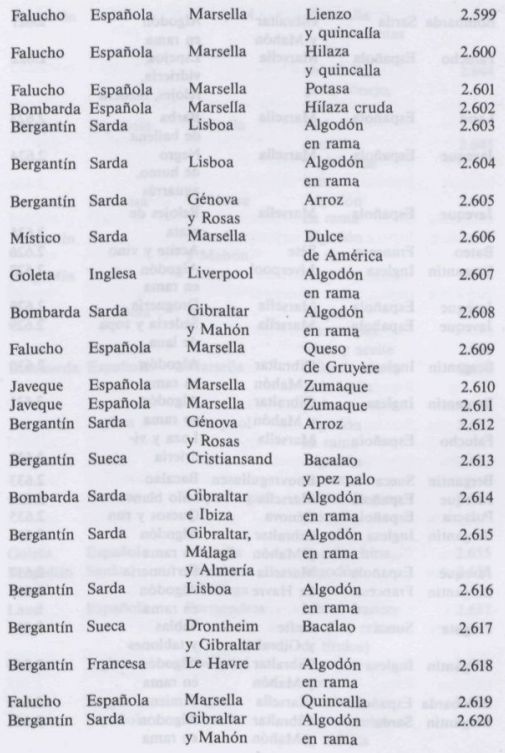




\begin{tabular}{|c|c|c|c|c|}
\hline Bombarda & Sarda & $\begin{array}{l}\text { Gibraltar } \\
\text { y Mahón }\end{array}$ & $\begin{array}{l}\text { Algodón } \\
\text { en rama }\end{array}$ & 2.621 \\
\hline Falucho & Española & Marsella & $\begin{array}{l}\text { Espejos, } \\
\text { vidrieria, } \\
\text { relojes, madera }\end{array}$ & 2.622 \\
\hline Laud & Española & Marsella & $\begin{array}{l}\text { Barba } \\
\text { de ballena }\end{array}$ & 23 \\
\hline Javeque & Española & Marsella & $\begin{array}{l}\text { Negro } \\
\text { de humo, } \\
\text { aguarrás }\end{array}$ & 2.624 \\
\hline Javeque & Española & Marsella & $\begin{array}{l}\text { Relojes de } \\
\text { plata }\end{array}$ & 2.625 \\
\hline Bateo & Francesa & Sète & Aceite y vino & 2.626 \\
\hline Bergantín & Inglesa & Liverpool & $\begin{array}{l}\text { Algodón } \\
\text { en rama }\end{array}$ & 2.627 \\
\hline Javeque & Española & Marsella & Droguería & 2.628 \\
\hline Javeque & Española & Marsella & $\begin{array}{l}\text { Sedería y ropa } \\
\text { de lana }\end{array}$ & 2.629 \\
\hline Bergantín & Inglesa & $\begin{array}{l}\text { Gibraltar } \\
\text { y Mahón }\end{array}$ & $\begin{array}{l}\text { Algodón } \\
\text { en rama }\end{array}$ & 2.630 \\
\hline Bergantín & Inglesa & $\begin{array}{l}\text { Gibraltar } \\
\text { y Mahón }\end{array}$ & $\begin{array}{l}\text { Algodón } \\
\text { en rama }\end{array}$ & 2.631 \\
\hline Falucho & Española & Marsella & $\begin{array}{l}\text { Loza y vi- } \\
\text { drieria }\end{array}$ & 2.632 \\
\hline Bergantin & Sueca & Bouvregullus & Bacalao & 2.633 \\
\hline Javeque & Española & Marsella & Hilo blanco & 2.634 \\
\hline Polacra & Española & Génova & Quesos y ron & 2.635 \\
\hline Bergantín I & Inglesa & $\begin{array}{l}\text { Gibraltar } \\
\text { y Mahón }\end{array}$ & $\begin{array}{l}\text { Algodón } \\
\text { en rama }\end{array}$ & 2.636 \\
\hline Javequ & Española & Marsella & Perfumería & 2.637 \\
\hline Bergantin & Francesa & Le Havre & $\begin{array}{l}\text { Algodón } \\
\text { en rama }\end{array}$ & 2.638 \\
\hline Fragata & Sueca & $\begin{array}{l}\text { Gefte } \\
\text { y Gibraltar }\end{array}$ & $\begin{array}{l}\text { Tablas } \\
\text { y tablones }\end{array}$ & 2.639 \\
\hline Bergantin I & Inglesa & $\begin{array}{l}\text { Gibraltar } \\
\text { y Mahón }\end{array}$ & $\begin{array}{l}\text { Algodón } \\
\text { en rama }\end{array}$ & 2.640 \\
\hline Bombarda & Española & Marsella & Pimienta negra & 2.641 \\
\hline Bergantin S & Sarda & $\begin{array}{l}\text { Gibraltar } \\
\text { y Mahón }\end{array}$ & $\begin{array}{l}\text { Algodón } \\
\text { en rama }\end{array}$ & 2.642 \\
\hline
\end{tabular}




\begin{tabular}{|c|c|c|c|c|}
\hline ergantín & Inglesa & Liverpool & $\begin{array}{l}\text { Quincalla } \\
\text { y herramientas }\end{array}$ & 2.6 \\
\hline Falucho & Española & Marsella & $\begin{array}{l}\text { Pieles: } \\
\text { chinchilla, } \\
\text { gato, conejo, } \\
\text { zorro }\end{array}$ & 2.644 \\
\hline Javeque & Española & Marsella & $\begin{array}{l}\text { Piel de } \\
\text { camello }\end{array}$ & 2.645 \\
\hline 25 & & & $\mathbf{y}$ piele & \\
\hline 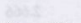 & & & liebre & \\
\hline Bergantín & Francesa & Le Havre & $\begin{array}{l}\text { Alg } \\
\text { en }\end{array}$ & 2.646 \\
\hline Bergantín & Sarda & Gibr & $\begin{array}{l}\text { Alg } \\
\text { en }\end{array}$ & 2.647 \\
\hline ergantin & Sarda & & n & 2.648 \\
\hline Javeque & Española & Mar & ses & 2.649 \\
\hline auc & Española & Marsella & $\mathrm{Vir}_{\mathrm{i}}$ & 2.650 \\
\hline Bombarda & Española & Marsella & rro & 2.651 \\
\hline Bergantín & Inglesa & Liverpool & x) & 2.652 \\
\hline ergantín & Sarda & Lisboa & án & 2.653 \\
\hline Galea & Danesa & Copenhague & $\begin{array}{l}\text { Tablas de pino } \\
\text { y duelas } \\
\text { de roble }\end{array}$ & 2.654 \\
\hline . & Española & Mar & 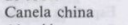 & 2.655 \\
\hline Bergantin & Sarda & $\begin{array}{l}\text { Gibr } \\
\text { y M }\end{array}$ & $x^{2}$ & 2.656 \\
\hline Laud & Espanola & Portvendres & $\begin{array}{l}\text { Libros france- } \\
\text { ses (hay relac. } \\
\text { de titulos) }\end{array}$ & 2.657 \\
\hline Goleta & Inglesa & Liverpool & $\begin{array}{l}\text { Algodón } \\
\text { rama }\end{array}$ & 2.658 \\
\hline & & & Bacalao & 2.659 \\
\hline Javeque & Española & Marsella & $\begin{array}{l}\text { Instrumentos } \\
\text { de música }\end{array}$ & 2.660 \\
\hline
\end{tabular}




\begin{tabular}{|c|c|c|c|c|}
\hline Falucho & Española & Marsella & $\begin{array}{l}\text { Hilo de hierro, } \\
\text { clavos y pelo } \\
\text { de brochas }\end{array}$ & 2.661 \\
\hline Laud & Española & Marsella & $\begin{array}{l}\text { Hilo de hierro } \\
\text { y agujas }\end{array}$ & 2.662 \\
\hline Javeque & Española & Marsella & Porcelana & 2.663 \\
\hline Falucho & Española & Marsella & $\begin{array}{l}\text { Quincalla } \\
\text { (hay relación) }\end{array}$ & 2.664 \\
\hline Falucho & Española & Marsella & Quincalla & 2.665 \\
\hline Escuna & Inglesa & Liverpool & $\begin{array}{l}\text { Algodón } \\
\text { en rama }\end{array}$ & 2.666 \\
\hline Bergantin & Sueca & Cristiansand & Bacalao y pez & 2.667 \\
\hline Bergantin & Inglesa & Liverpool & $\begin{array}{l}\text { Algodón } \\
\text { en rama }\end{array}$ & 2.668 \\
\hline Laud & Española & Marsella & Añil & 2.669 \\
\hline Bergantín & Inglesa & Liverpool & $\begin{array}{l}\text { Hojalata, } \\
\text { estaño }\end{array}$ & 2.670 \\
\hline Falucho & Española & Marsella & $\begin{array}{l}\text { Granata } \\
\text { pimienta } \\
\text { de Aviñón }\end{array}$ & 2.671 \\
\hline Goleta & Española & Génova & Pimienta negra & 2.672 \\
\hline Javeque & Española & Marsella & Manna & 2.673 \\
\hline Bergantín & Sarda & Lisboa & $\begin{array}{l}\text { Algodón } \\
\text { en rama }\end{array}$ & 2.674 \\
\hline Falucho & Española & Marsella & $\begin{array}{l}\text { Cuerpos vacu- } \\
\text { nos al pelo }\end{array}$ & 2.675 \\
\hline Laud & Española & Portvendres & Hilo de hierro & 2.676 \\
\hline Bergantín & Sueca & $\begin{array}{l}\text { Gefte } \\
\text { y Gibraltar }\end{array}$ & $\begin{array}{l}\text { Tablones } \\
\text { de pino }\end{array}$ & 2.677 \\
\hline Javeque & Española & Marsella & Tripas de vaca & 2.678 \\
\hline Bergantín & Sueca & Cristiansand & $\begin{array}{l}\text { Bacalao } \\
\text { y pez palo }\end{array}$ & 2.679 \\
\hline Falucho & Española & Marsella & Quincalla & 2.680 \\
\hline Bergantín & Sarda & Lisboa & $\begin{array}{l}\text { Algodón } \\
\text { en rama }\end{array}$ & 2.681 \\
\hline Javeque & Española & Marsella & Quincalla (rel.) & 2.682 \\
\hline Falucho & Española & Marsella & $\begin{array}{l}\text { Vidrios } \\
\text { y espejos }\end{array}$ & 2.683 \\
\hline Bergantín & Sueca & $\begin{array}{l}\text { Drontheim } \\
\text { y Gibraltar }\end{array}$ & Bacalao & 2.684 \\
\hline
\end{tabular}




\begin{tabular}{|c|c|c|c|c|}
\hline Javeque & Española & Marsella & $\begin{array}{l}\text { Pieles } \\
\text { becerro } \\
\text { al pelo }\end{array}$ & 2.685 \\
\hline Bergantín & Francesa & Le Havre & $\begin{array}{l}\text { Algodón } \\
\text { en rama }\end{array}$ & 2.686 \\
\hline Falucho & Española & Marsella & Lencería (rel.) & 2.687 \\
\hline Javeque & Española & Marsella & Telas de lino & 2.688 \\
\hline Polacra & Francesa & La Habana & $\begin{array}{l}\text { Subasta } \\
\text { de ramos y } \\
\text { botes por } \\
\text { naufragio }\end{array}$ & $x^{2}$ \\
\hline Polacra & Francesa & La Habana & $\begin{array}{l}\text { Id. varios } \\
\text { efectos o.n. }\end{array}$ & 2.690 \\
\hline Polacra & Francesa & La Habana & $\begin{array}{l}\text { Id. varios } \\
\text { efectos o.n. }\end{array}$ & 2.691 \\
\hline Polacra & Francesa & La Habana & $\begin{array}{l}\text { Id. varios } \\
\text { efectos o.n. }\end{array}$ & 2.692 \\
\hline Polacra & Francesa & La Habana & $\begin{array}{l}\text { Id. varios } \\
\text { efectos o.n. }\end{array}$ & 2.693 \\
\hline Polacra & Francesa & La Habana & $\begin{array}{l}\text { Id. varios } \\
\text { efectos o.n. }\end{array}$ & 2.694 \\
\hline Polacra & Francesa & La Habana & $\begin{array}{l}\text { Id. varios } \\
\text { efectos o.n. }\end{array}$ & 2.695 \\
\hline Polacra & Francesa & La Habana & $\begin{array}{l}\text { Id. varios } \\
\text { efectos o.n. }\end{array}$ & 2.696 \\
\hline Javeque & Española & Marsella & $\begin{array}{l}\text { Hilo de hierro } \\
\text { y agujas }\end{array}$ & 2.697 \\
\hline Javeque & Española & Marsella & $\begin{array}{l}\text { Cilindros y } \\
\text { agujas para } \\
\text { máquinas }\end{array}$ & 2.698 \\
\hline Javeque & Española & Marsella & $\begin{array}{l}\text { Herramientas y } \\
\text { quincalla (rel.) }\end{array}$ & 2.699 \\
\hline Javeque & Española & Marsella & $\begin{array}{l}\text { Peleteria: liebre } \\
\text { y gato }\end{array}$ & 2.700 \\
\hline Javeque & Española & Marsella & Sederia & 2.701 \\
\hline Javeque & Española & Marsella & Quincalla (rel.) & 2.702 \\
\hline Falucho & Española & Marsella & Hilaza cruda & .2 .703 \\
\hline Javeque & Española & Marsella & $\begin{array}{l}\text { Vidrios } \\
\text { para ventanas }\end{array}$ & 2.704 \\
\hline
\end{tabular}




\begin{tabular}{|c|c|c|c|c|}
\hline Javeque & Española & Marsella & $\begin{array}{l}\text { Quincalla, } \\
\text { merceria, jabón } \\
\text { y relojes de } \\
\text { faltriguera }\end{array}$ & 2.705 \\
\hline Bergantín & Sueca & Gothemburgo & $\begin{array}{l}\text { Tablas y tablo- } \\
\text { nes de pino }\end{array}$ & 2.706 \\
\hline Javeque & Española & Marsella & Alfileres & 2.707 \\
\hline Javeque & Española & Marsella & $\begin{array}{l}\text { Vino, papel, } \\
\text { quincalla (rel.) }\end{array}$ & 2.708 \\
\hline Javeque & Espanola & Marsella & Alefines & 2.709 \\
\hline Javeque & Española & Marsella & Quincalla (rel.) & 2.710 \\
\hline Javeque & Española & Marsella & Pieles de liebre & 2.711 \\
\hline Javeque & Española & Marsella & Lanería & 2.712 \\
\hline Bergantín & Inglesa & Liverpool & $\begin{array}{l}\text { Algodón } \\
\text { en rama }\end{array}$ & 2.713 \\
\hline Javeque & Española & Marsella & $\begin{array}{l}\text { acero, } \\
\text { la (rel.) }\end{array}$ & 2.714 \\
\hline Javeque & Española & Marsella & Quincalla (rel.) & 2.715 \\
\hline Falucho & Española & Marsella & lla (rel.) & 2.716 \\
\hline Goleta & Inglesa & Liverpool & $\begin{array}{l}\text { Algodón } \\
\text { en rama }\end{array}$ & 2.717 \\
\hline Javeque & Española & Marsella & $\begin{array}{l}\text { Hilaza } \\
\text { y lenceria }\end{array}$ & 2.718 \\
\hline Bergantín & Sue & Cristiansand & $\begin{array}{l}\text { Bacalao } \\
\text { y pez palo }\end{array}$ & 2.719 \\
\hline Bergantin & Sarda & $\begin{array}{l}\text { Gibraltar } \\
\text { y Mahón }\end{array}$ & $\begin{array}{l}\text { Pimienta de } \\
\text { de tabaco }\end{array}$ & ר \\
\hline Laud & Española & Portvendres & $\begin{array}{l}\text { Pañuelos, lana, } \\
\text { foulards, seda, } \\
\text { algodón }\end{array}$ & 2.721 \\
\hline Javec & Española & Marsella & Illa (rel.) & 2.722 \\
\hline Javeque & Espanola & Marsella & Vidriería & 2.723 \\
\hline Javeque & Española & Marsella & Lenceria (rel.) & 2.724 \\
\hline Bergantín & Sueca & $\begin{array}{l}\text { Drontheim } \\
\text { y Gibraltar }\end{array}$ & Tablas pino & 2.725 \\
\hline Javeque & Española & Marsella & Jamones & 2.726 \\
\hline
\end{tabular}


Clase de Nacionalidad Procedencia

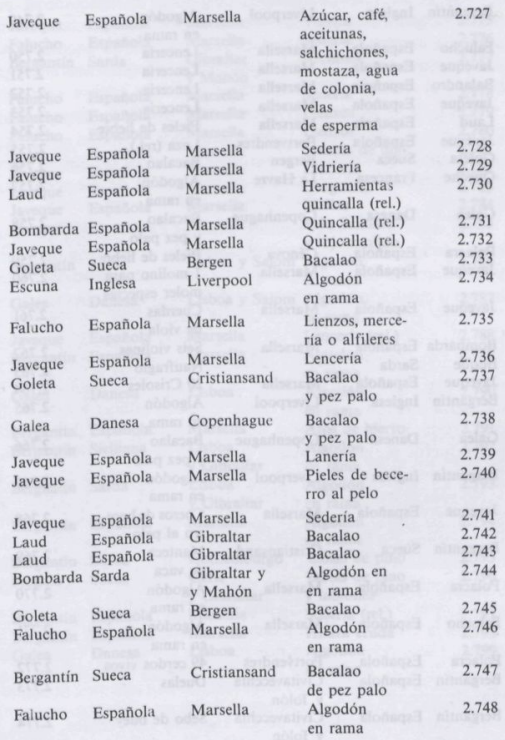




\begin{tabular}{|c|c|c|c|c|}
\hline Bergantín & Inglesa & Liverpool & $\begin{array}{l}\text { Algodón } \\
\text { en rama }\end{array}$ & 2.749 \\
\hline Falucho & Española & Marsella & Lenceria & 2.750 \\
\hline Javeque & Española & Marsella & Lencería & 2.751 \\
\hline Balandro & Española & Marsella & Lenceria & 2.752 \\
\hline Javeque & Española & Marsella & Lenceria & 2.753 \\
\hline Laud & Española & Marsella & Pieles de liebre & 2.754 \\
\hline Javeque & Española & Portvendres & Loza (rel.) & 2.755 \\
\hline Goleta & Sueca & Bergen & Bacalao & 2.756 \\
\hline Queche & Francesa & Le Havre & $\begin{array}{l}\text { Algodón } \\
\text { en rama }\end{array}$ & 2.757 \\
\hline Galea & Danesa & Copenhague & $\begin{array}{l}\text { Bacalao } \\
\text { y pez palo }\end{array}$ & 2.758 \\
\hline Polacra & Española & Génova & Pieles de liebre & 2.759 \\
\hline Javeque & Española & Marsella & $\begin{array}{l}1 \text { molino para } \\
\text { moler especias }\end{array}$ & 2.760 \\
\hline Javeque & Española & Marsella & $\begin{array}{l}\text { Cuerdas } \\
\text { de viola }\end{array}$ & 2.761 \\
\hline Bombarda & Española & Marsella & Seis violines & 2.762 \\
\hline Buque & Sarda & & Naufragio & 2.763 \\
\hline Javeque & Española & Marsella & 20 Crisoles & 2.764 \\
\hline Bergantín & Inglesa & Liverpool & $\begin{array}{l}\text { Algodón } \\
\text { en rama }\end{array}$ & 2.765 \\
\hline Galea & Danesa & Copenhague & $\begin{array}{l}\text { Bacalao } \\
\text { y pez palo }\end{array}$ & 2.766 \\
\hline Bergantin & Inglesa & Liverpool & $\begin{array}{l}\text { Algodón } \\
\text { en rama }\end{array}$ & 2.767 \\
\hline Javeque & Española & Marsella & $\begin{array}{l}\text { Cueros de bece- } \\
\text { rro al pelo }\end{array}$ & 2.768 \\
\hline Bergantin & Sueca & Cristiansand & $\begin{array}{l}\text { Manteca } \\
\text { de vaca }\end{array}$ & 2.769 \\
\hline Polacra & Española & Marsella & $\begin{array}{l}\text { Algodón } \\
\text { en rama }\end{array}$ & 2.770 \\
\hline Falucho & Espanola & Marsella & $\begin{array}{l}\text { Algodón } \\
\text { en rama }\end{array}$ & 2.771 \\
\hline Polacra & Española & Portvendres & 49 cerdos vivos & 2.772 \\
\hline Bergantín & Española & $\begin{array}{l}\text { Civitavecchia } \\
\text { y Tolón }\end{array}$ & Duelas & 2.773 \\
\hline $\mathrm{Be}$ & Española & $\begin{array}{l}\text { Civitavecchia } \\
\text { y Tolón }\end{array}$ & Sebo de buey & 4 \\
\hline
\end{tabular}


Clase de Nacionalidad Procedencia Mercaderias Núm. Hoja barco

\begin{tabular}{|c|c|c|c|c|}
\hline Javeque & Española & Marsella & Vidrios & 2.775 \\
\hline Falucho & Española & Marsella & Sedería & 2.776 \\
\hline Bergantín & Sarda & $\begin{array}{l}\text { Gibraltar } \\
\text { y Mahón }\end{array}$ & Archiota & 2.777 \\
\hline Falucho & Española & Marsella & Sedería & 2.778 \\
\hline Falucho & Española & Marsella & Lienzos & 2.779 \\
\hline Falucho & Española & Marsella & Lienzos & 2.780 \\
\hline Laud & Española & Marsella & Sedería de lino & 2.781 \\
\hline Javeque & Española & Marsella & Lencería & 2.782 \\
\hline Javeque & Española & Marsella & Drogueria & 2.783 \\
\hline Javeque & Española & Marsella & Mallas & 2.784 \\
\hline Javeque & Española & Marsella & $\begin{array}{l}\text { Palo Sándalo } \\
\text { y rojo molido }\end{array}$ & 2.785 \\
\hline Bergantín & Sarda & Lisboa y Salom & $\begin{array}{l}\text { Algodón } \\
\text { en rama }\end{array}$ & 2.786 \\
\hline Galea & Danesa & Lisboa y Salom & $\begin{array}{l}\text { Algodón } \\
\text { en rama }\end{array}$ & 2.787 \\
\hline Javeque & Española & Marsella & Lencería (rel.) & 2.788 \\
\hline Bergantin & Espanola & Marsella & $\begin{array}{l}\text { Algodón } \\
\text { en rama }\end{array}$ & 2.789 \\
\hline Galea & Danesa & Lisboa & $\begin{array}{l}\text { Algodón } \\
\text { en rama }\end{array}$ & 2.790 \\
\hline Bergantin & Española & Marsella & Aros de hierro & 2.791 \\
\hline Bergantín & Siciliana & $\begin{array}{l}\text { Lisboa } \\
\text { y Gibraltar }\end{array}$ & Algodón & 2.792 \\
\hline Bergantín & Sarda & $\begin{array}{l}\text { Lisboa } \\
\text { y Gibraltar }\end{array}$ & $\begin{array}{l}\text { Algodón } \\
\text { en rama }\end{array}$ & 2.793 \\
\hline Bergantín & Española & Marselia & $\begin{array}{l}\text { Algodón } \\
\text { en rama }\end{array}$ & 2.794 \\
\hline Bergantín & Sueca & Gothemburgo & Tablas de pino & 2.795 \\
\hline Fragata & Sueca & $\begin{array}{l}\text { Gefte } \\
\text { y Gibraltar }\end{array}$ & $\begin{array}{l}\text { Tablas de pino } \\
\text { y tablones }\end{array}$ & 2.796 \\
\hline Bergantín & Española & Marsella & Sedería (rel.) & 2.797 \\
\hline Bergantín & Española & Marsella & Hilaza cruda & 2.798 \\
\hline Galea & Danesa & Lisboa & $\begin{array}{l}\text { Algodón } \\
\text { en rama }\end{array}$ & 2.799 \\
\hline
\end{tabular}


Habitualmente las hojas de entrada del extranjero estaban tramitadas con un certificado expedido por un cónsul del puerto de procedencia firmada y refrendada con el sello del Consulado, que les servía a los capitanes de guía de navegación, ya que estaban expedidos según las ordenanzas y hacían constar el nombre de la embarcación, el nombre del capitán, la nacionalidad y el puerto destinatario. Seguidamente se especificaba la carga, el pais, el consignador y el consignatario.

Esta guía de navegación servía de control de la carga, ya que tenían que corresponder a la presentada por el capitán en el Consulado para su despacho. Si transportase otros efectos en lugar de los que declaraban, quedaban prevenidos de las penas que incurrían.

Este control nos ha permitido conocer en el registro que describimos los veleros que se dedicaban a la navegación de altura y las diferentes clases de aparejo con que estaban dotados: velas latinas o cuadradas, así como gran profusión de detalles náuticos.

Ofrece gran interés la relación de mercancías, que constituyen una expresión gráfica de las demandas, tanto a efectos de comercio interior como las materias destinadas a una ulterior manipulación industrial, entre estas últimas las aplicadas a la industria textil: algodón en rama, algodón hilado, hilaza blanca o cruda, tela fina de lana, lienzos, sederías, telas de lino, etc. o productos manufacturados: pañuelos de lana, foulards, etc. además de relojes, porcelanas, espejos, instrumentos de música.

No sólo se traficaba con productos y bienes, sino también con libros. Tal como aparece en la hoja núm. 2657 procedente de Portvendres. En la mera enumeración de las materias a que estaban dedicados estos textos: economía, política, arquitectura, pintura, ingeniería de caminos y puertos, finanzas, aduanas, barcos, comercio, etc., se refleja una estadistica cultural de la época, de toda la expresión de una demanda científica, que interpretada en el sentido contrario nos muestra el vacío en cuanto que las necesidades editoriales concretas señalan las carencias propias de nuestro país.

Las cargas procedentes de La Habana eran remos, botes y varios efectos recuperados de naufragios para subastar. En rea- 
lidad era una actividad mercantil residual con el comercio americano.

Otra faceta también importante, que se extrae de la lectura del libro registro de fletes, es el esquema de las rutas de navegación que describirán las diferentes naves en sus continuas singladuras, enfocadas siempre a la obtención de mercancías para su posterior transporte. Esto nos permitirá conocer qué puertos eran más activos en la contratación de fletes.

En Europa, los más visitados eran:

Francia: Sète

Le Havre

Marsella

Portvendres

Tolón
Inglaterra: Gibraltar

Liverpool

Italia:

Civitavecchia

Génova
Noruega: Bergen

Cristiansand

Drontheim

Suecia: Estocolmo

Gefte

Gothemburgo

Circunstancialmente, el desarrollo de la navegación a vapor, las dificultades de encontrar cargas de regreso a Cuba, la subida de los derechos del tasaje, cuyo consumo disminuyó con la abolición de la esclavitud, hizo que la navegación entrase en decadencia y se produjese el amarre definitivo de más de sesenta barcos de la costa.

Asimismo, en 1850, paralelamente, comienza a desarrollarse la navegación a vapor, que adquirió un auge entre los años de 1856-1863 conviviendo con los viejos barcos de vela. La nueva Marina Mercante quedó constituída sin que disminuyese la marina de vela, junto a los nuevos barcos de vapor, que permitian una mayor estabilidad en el tráfico de mercancias, ya que sus rutas eran independientes.

Además, la apertura del canal de Suez, que devolvía al Mediterráneo la antigua supremacía, varió el centro de gravedad comercial del mundo.

Con estos precedentes, sumados a las obras del puerto de Barcelona, se abre una nueva etapa de la navegación con unas estructuras que merecerán un estudio profundo en nuevas fuentes documentales. 